\title{
MOVEMENT DISORDERS SECONDARY TO LONG-TERM TREATMENT WITH CYCLOSPORINE A
}

\author{
Renato P. Munhoz', Helio A.G. Teive', Francisco M.B. Germiniani', \\ Júlio C. Gerytch Jr'., Daniel S. Sá', Marco A. Bittencourt², \\ Ricardo Pasquini², Carlos H.F. Camargo', Lineu César Werneck ${ }^{1}$
}

\begin{abstract}
Objective: To analyze the prevalence, severity and functional interf e rence of movement diso rders (MD) secondary to chronic use of cyclosporine A (CSA). Method: We conducted a cross-sectional study of 60 patients ( $58.3 \%$ male) with mean age 23.1 (3-75) years, followed at the Bone Marrow Transplantation Service of the Hospital de Clínicas of the Federal University of Paraná, Brazil, taking CsA for at least six months. Our protocol included clinical data, assessment of functional interf e rence of symptoms and neurological examination including observation and grading of MD. Results: Eight (13.3\%) subjects reported the presence of tremor at the moment of interview and $29(48.3 \%)$ recalled this symptom at some point during treatment. Neurological examination identified $14(23.3 \%)$ subjects with MD: upper limb symmetric action tremor in $13(21.6 \%)$ and parkinsonism (rigidity and bradykinesia) in $1(1.7 \%)$. No other MD was detected. The mean scores indicated mild clinical signs in all cases. Symptoms were conside red subjectively mild with no functional interf e rence. Conclusion: Almost one quarter of patients using CsA chronically presented MD, almost always mild and transitory action tremor, with minimal interference on daily living activities, not requiring any form of intervention in the majority of cases.
\end{abstract}

KEY WORDS: cyclosporine A, tremor, movement disorders, bone marrow transplant.

\begin{abstract}
Transtornos do movimento secundários ao tratamento prolongado com ciclosporina $\mathbf{A}$
RESUMO - Objetivo: Analisar a prevalência, gravidade e interferência funcional de transtornos do movimento (TM) secundários ao uso crônico de ciclosporina A (CsA). Método: Realizamos um estudo transversal em 60 pacientes (58.3\% do sexo masculino) com idade média de 23.1 (3-75) anos, acompanhados pelo Serviço de Transplante de Medula Óssea do Hospital de Clínicas da Universidade Federal do Paraná, usando CsA por pelo menos seis meses. A avaliação incluiu dados clínicos, interferência funcional de possíveis sintomas e exame neurológico incluindo observação e graduação de TM. Resultados: Oito (13.3\%) ent revistados relataram tremor no momento da entrevista e $29(48.3 \%)$ em alguma fase do tratamento. O exame neurológico identificou $14(23.3 \%)$ pacientes com TM: $13(21.6 \%)$ tremor de ação simétrico de membros superiores e em 1 (1.7\%) parkinsonismo (rigidez e bradicinesia). Nenhum outro TM foi detectado. Os escores médios indicaram quadros leves em todos os casos. Os sintomas foram também considerados subjetivamente leves e sem interferência funcional. Conclusão: Quase um quarto dos pacientes usando CsA cronicamente apresenta TM, quase sempre tremor de ação leve e transitório, interferindo pouco funcionalmente, não requerendo intervenção na maioria dos casos.
\end{abstract}

PALAVRAS-CHAVE: ciclosporina A, tremor, transtornos do movimento, transplante de medula óssea.

Cyclosporine A ( CsA) is an immunosuppressive agent used broadly in the prevention of rejection of solid organ transplantation due to its effect as a reversible inhibitor of $T_{4}$ lymphocytes activity and the subsequent release of lymphokines. Although not a myelosuppressant, its use is limited by several side effects including nephrotoxicity and hepatotoxicity, hypertension, gingival hyperplasia, hypertrichosis and opportunistic infections ${ }^{1}$.
With the increasing experience with the use of CsA in several centers, neurological complications, once ra rely described, are now reported in up to $40 \%$ of patients, requiring dosage adjustment in one forth of all cases ${ }^{2}$.

The majority of these side effects are related to the central nervous system, but cases of peripheral neuropathy were also occasionally described. The most commonly described complications inclu-

Neurology ${ }^{1}$ and Bone Marrow Transplantation² Service of Hospital de Clínicas of Federal University of Paraná, Curitiba PR, Brazil. Received 9 September 2004, received in final form 27 December 2004. Accepted 16 March 2005. 
de confusion, disorientation, a wide variety of changes in behavioral and in the level of conscience, seizures, cortical blindness, aphasia, pyramidal signs and movement disorders (MD) ${ }^{3}$. Among this particular group, tremor is the best recognized ${ }^{4}$, but case reports of other forms of MD exist in the literature including ataxia ${ }^{5}$, parkinsonism ${ }^{6,7}$, myoclonus $^{8}$ and chorea9.

The objectives of our study were to analyze the prevalence of MD among individuals using CsA chronically after bone marrow transplantation (BMT) and to assess the severity and functional interference of the possible findings.

\section{METHOD}

We performed an observational study (cross sectional) assessing 60 patients [35 (58.3\%) male and 25 (41.7\%) female] with mean age 23.1 (3-75) years, followed by the Service of BMT of the Hospital de Clínicas of the Federal University of Paraná (HC-UFPR). Time for diagnosis of the underlying disorder varied from 0.1 to 6 years (mean 1.6). Previously to BMT, all were submitted to other forms of treatment including chemotherapy, transfusions or both.

Indications for BMT were severe aplastic anemia in $41(68.3 \%)$ cases, chronic myeloid leukemia in 11 (18.3\%) cases, acute myeloid leukemia in $4(6.7 \%)$, myelodysplasia in $3(5 \%)$ and acute lymphocytic leukemia in $1(1.7 \%)$. All had documented history of CsA use continuously for at least of six months, preceding the evaluation and following BMT in a target maintenance dosage of $5 \mathrm{mg} / \mathrm{kg} /$ day (mean 4,35 mg/kg/day) as part of a protocol established by the service of BMT [associated with methotrexate in 50 (83.3\%) and/or corticosteroids in 25 (41.6\%)]. According to the same protocol, all received prophylac- tic sulfamethoxazole, trimetropine, acyclovir and norfloxacin. Those who were clinically decompensated, had clinical or paraclinical signs of current infection or with a history of drugs that can induce MD such as neuroleptics, tricyclic antidepressants and serotonin reuptake inhibitors, calcium channel blockers, aminophilin and antiepileptics were excluded.

The assessments were performed after a mean 223.1 (192-367) days post-BMT and included demographic and t reatment data, and a directed questionnaire inquiring specifically on the subjective presence of MD described in lay terms. If the answer to this questionnaire was positive, its interference on activities of daily living (ADLs) was assessed using practical examples. One of the authors with experience in MD (DSS) completed a stan$\mathrm{d}$ a rdized protocol that included body weight measurement, application of the Bain et al. ${ }^{10}$ scale for tre mors and the Unified Parkinson's Disease Rating Scale ${ }^{11}$ part III (UPDRS-III), as well as the observation and rating of other possible MD (ataxia, dystonias, chorea and myoclonus).

The HC-UFPR ethics commitee approved the study and all included subjects gave their informed consent before the beginning of the evaluation process.

\section{RESULTS}

Eight (13.3\%) out of 60 interviewed subjects re p o rted the subjective finding of MD at the time of assessment, in all cases tremor. This number increased to 29 (48.3\%) when the question embraced the retrospective finding of these symptoms at any point of CsA treatment, 21 (72.4\%) of these were observed during the first three months of treatment, not requiring any form of intervention. The objective assessment perf o rmed by the examiner found 14 (23.3\%) patients with MD: 13 (21.6\%)

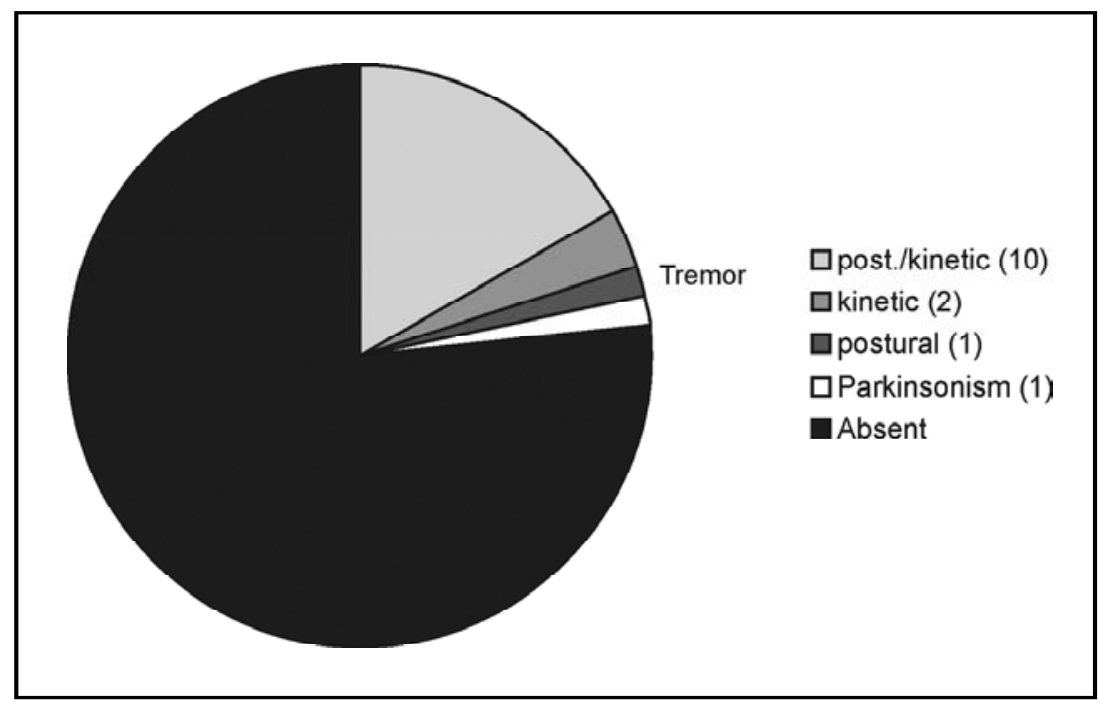

Figure. Movement disorders in 60 patients taking CSA. 
with action tremor (postural or kinetic) and one $(1.7 \%)$ with parkinsonism (Figure). No other form of abnormal movement was re p orted by the subjects of identified by the examiner.

All the eight cases of tremor re ported subjectively were confirmed objectively by physical assessment. Five additional subjects were identified with this signal did not mentioned it during interview; the same observation was valid for the one individual with parkinsonism.

In all 13 cases of action tremor, the phenomenological description was that of a symmetric upper extremities movement. One $(1.67 \%)$ of these described as purely postural. In the remaining 10 $(16.6 \%)$ cases, tremor had a concomitance of a kinetic component of the same or lower intensity. Two (3.3\%) presented tremor that was more noticeable during movement with no evident dysmetria or intentional tremor (Figure). One individual presented concomitance of symmetric tremor in the lower limbs.

Mean upper extremity Bain et al. ${ }^{10}$ tremor scale scorewas 3.8 (2-7) of possible 20 points, indicative of mild tremor. The subject with parkinsonism had a total UPDRS-III score of 6 out of possible 56 points, with mild scores on items related to rigidity and bradykinesia, with no resting tremor or postural instability. In accordance with these scores, symptoms were considered subjectively mild with no ADL functional interference, except for one case. Duration of CsA treatment in the individuals with tremor did not differ significantly in comparison with those who presented no signs or symptoms.

\section{DISCUSSION}

The results of our study showed that almost one forth of all subjects receiving CsA chronically presented with MD, almost exclusively action tremor. This finding, though, is mild as demonstrated by the observation the examiner and the patient, been frequently transitory and not requiring any form of intervention in the majority of cases. Our study differed from others that evaluated adverse effects secondary to CsA treatment because it included exclusively patients taking this drug for at least 6 months, excluding symptoms reactive to introduction and dosage adjustment. In accordance with this observation, almost half of the interviewed subjects retrospectively reported the presence of transient tremors that did not required any form of change in therapeutic regimen as well as any other form of intervention. Previous studies assessing the presence of neurological complications emphasized part of our findings: Pirsch et al. ${ }^{3}$, for example, found postural tremor prospectively in $33.8 \%$ of subjects taking CsA for one year, the majority during the first 3 months of treatment. Accordingly, two studies evaluating side effects in patients taking CsA found an incidence of tremor varying from 12 to $21 \% \%^{8,12}$ concluding that this symptom is generally mild and does not require dosage adjustment or any form of intervention. These studies demonstrated that tremor usually occurs during initial attempts to increase daily dosage, but is also described in individuals receiving stable maintenance dosages within therapeutic blood levels, as in the cases presented here. The only study that analyzed late neurological complications of CsA was the one published by Trocha et al. ${ }^{13}$ including patients taking CsA for at least 5 months, with findings very similar to ours: $28 \%$ presented tremor with minimal interfe rence on ADL. On the other hand, one form complex neurotoxic syndrome that invariably includes postural tremor and confusion was described in the series published by Wijdicks et al. ${ }^{8}$ and Menegaux et al. ${ }^{14}$ almost always related to elevated serum levels and/or intravenous CsA infusion.

Kinetic tremor, isolated or as a part of a cerebellar syndrome, seems to be less frequent than postural tremor ${ }^{15}$. Other MD are rare and described only in case reports. The series of Wijdicks et al. ${ }^{8}$, for instance, describes 3 cases of myoclonus with speech disturbances responsive to reduction of CsA dosage. Two cases of chorea (one of these possibly pseudoathetosis secondary to peripheral neuropathy) related to CsA have been published in the medical literature, the first described in a series of 46 patients post-BMT ${ }^{16}$ and the second described after liver transplantation (LT) in Wilson's disease ${ }^{9}$. Cerebellar ataxia was described in up to $5 \%$ of patients starting treatment, specially following renal transplantation (RT) in children ${ }^{17,18}$. Belli et al. ${ }^{5}$ described one case of cerebellar syndrome detected 6 months after LT, symptoms improved after CsA withdrawal. Although used for prevention of rejection of neural xeno and allogenic transplantation in Parkinson's disease (PD) and possibly providing improvement in motor aspects of animal models of this disorder ${ }^{19-21}$, CsA has been considered the cause of parkinsonism in a few case reports. Wasserstein and Honig ${ }^{7}$ reported two patients with resting tremor and bradykinesia taking CsA post$B M T$, one responded to levodopa while the one 
that did not tolerate levodopa improved after immunosuppressant dosage was reduced. Another case report describes a patient with symmetric resting tremor, rigidity and bradykinesia non-responsive to levodopa and trihexyphenidyl but improved when CsA was withdrawn after $\mathrm{RT}^{6}$. The case of parkinsonism observed in our study did not require specific treatment because symptoms did not interfe rewith the ADL. It was not possible to establish a cause and effect correlation among CsA and parkinsonian signs since the individual was in the age range for idiopathic PD.

Possible risk factors for neurological complications of CsA include intensive pre- transplantation chemotherapy, radiation, drug interactions, metabolic disturbances, tissue rejection, fluid retention and hypertension related to corticosteroids, hypercholesterdemia, hypomagnesemia and aluminum overload in $\mathrm{RT}^{4}$. Other drugs that interfe re with CsA metabolism may increase blood levels to potentially toxic levels ${ }^{4}$. Although anatomopathological studies did not find a histological substrate for tremor and other MD in patients taking $\mathrm{Cs}^{15}$, the mechanism for neurotoxicity seems to be related primarily to the fact of CsA being highly lipophilic, crossing easily the blood brain barrier ${ }^{4}$. From this point on potentially reversible interactions may happen interfering with central neuronal circuits including direct changes in neurotransmission and receptor function, phosphorylation pathways and regulation of transcriptional factors ${ }^{6}$. Fienberg et al. ${ }^{22}$ demonstrated that CsA modulates dopaminergic transmission through its stimulating effect on phosphorylation of dopamine and adenosine dependent phosphoprotein 3'5' monophosphate (DARPP-32) on medium spined striatal neurons. DARPP-32 has a fundamental effect on dopaminergic neurotransmission and CsA incre ases its levels up to 17 -fold ${ }^{23}$. Accordingly, this CsA dopaminergic modulation seems to have an inductor effect of rodent hyperactivity ${ }^{24}$. On the other hand, CsA potentiates domperidone-induced antidopaminergic effect ${ }^{25}$. Amongst such evidences, the reasons why certain patients manifest hyper or hypokinetic syndromes, as well as the fact that such toxicity being manifested most frequently as postural tremor remains obscure.

Our study has important limitations: although been indicated in several situations, CsA evaluated here exclusively post-BMT, hence our findings should not be extensive universally even if other studies in different population have provided similar results. It would be important to correlate symptoms not only with the dosage taken but also with serum levels. This correlation was not performed initially because it would only be valid if the exact moment when the MD would be detected clinically could be determined for each subject and, at that moment, serum levels measured. This can only be perf o rmed prospectively, using a methodological process that escapes from the one proposed for our study. We could not speculate any hypothesis linking the presence of the MD with treatment timing or its improvement with CsA dosage reduction since these side effects are usually mild, transient and also because in the vast majority of cases the drug was been used on its lowest effective daily dosage. Another limitation was the lack of a control group. This problem was assumed considering that a healthy control gro up would bring significant biases for being an entirely distinct population in respect to potential neuropathological substrates (underlying condition, preBMT treatment, transplantation, etc) that may predispose our patients to MD. On the other hand, once all patients received the same drug regimen, we cannot count on the possibility of a comparison with a group that is not receiving this form of treatment. The only form of comparison that would avoid such bias would be between groups receiving diff e rent forms immunosuppressive regimens, such as tacrolimus versus $\mathrm{Cs} A$, OKT3 versus $\mathrm{CsA}^{3,13}$. Once again this possibility was not feasible by the fact that all studied subjects were following the same protocol established by the Service of BMT of the HC-UFPR.

We conclude that action tremor is the most common MD in patients treated with CsA, it is re Iatively more frequent in the beginning of treatment, being reported retrospectively in almost half of the individuals on our study. The assessment after at least 6 months demonstrated the transient character of this complication that has minimal if any impact on $A D L$ and almost never requires specific treatment. Therefore, the initial approach to the patient taking CsA who presents this form of side effect should be reassuring about its benign and transient character. In the rare cases when there is significant functional interf e rence, the interventions described in the literature can be resumed to CsA dosage adjustment or symptomatic tre atment directed to the specific $\mathrm{MD}^{4,7}$. 


\section{REFERENCES}

1. Kahan BD. Cyclosporine. N Engl J Med 1989;321:1725-1738.

2. Patchell RA. Neurological complications of organ transplantation. Ann Neurol 1994;36:688-703.

3. Pirsch JD, Miller J, Deierhoi MH, Vincenti F, Filo RS. A comparison of tacrolimus (FK506) and cyclosporine for immunosuppression after cadaveric renal transplantation. FK506 Kidney Transplant Study Group. Transplantation 1997;63:977-983.

4. Gijtenbeek JM, van den Bent MJ, Vecht CJ. Cyclosporine neurotoxicity: a review. J Neurol 1999;246:339-346.

5. Belli LS, De Carlis L, Romani F, et al. Dysarthria and cerebellar ataxia: late occurrence of severe neurotoxicity in a liver transplant recipient. Transpl Int 1993;6:176-178.

6. Kim HC, Han SY, Park SB, Suh SJ. Parkinsonism during cyclosporine t reatment in renal transplantation. Nephrol Dial Transplant 2002;17: 319-321.

7. Wasserstein PH, Honig LS. Parkinsonism during cyclosporine treatment. Bone Marrow Transplant 1996;18:649-650.

8. Wijdicks EF, Wiesner RH, Krom RA. Neurotoxicity in liver transplant recipients with cyclosporine immunosuppression. Neurology 1995;45:1962-1964.

9. Combarros O, Fabrega E, Polo JM, Berciano J. Cyclosporine-induced chorea after liver transplantation for Wilson's disease. Ann Neurol 1993;33:108-109.

10. Bain PG, Findley LJ, Atchison P, et al. Assessing tremor severity. J Neurol Neurosurg Psychiatry 1993;56:868-873.

11. Fahn S, Elton RL, and members of the UPDRS Development Committee. Unified Parkinson's disease rating scale. In: Fahn S, Marsden CD, Calne D, Goldstein M, (eds). Recent developments in Parkinson's disease. New York: MacMillan, 1987:153-163.

12. O'Sullivan DP. Convulsions associated with cyclosporin A. Br Med J 1985; 290: 858

13. Trocha K, Winkler M, Haas J, Ringe B, Wurster U, Ehrenheim C. Neurological examinations after liver transplantation concerning patients under corticosteroid immunosuppression and either FK 506 or cyclosporin. Transpl Int 1994;7(Suppl)1:S43-S49.
14. Menegaux F, Keeffe EB, Andrews BT, et al. Neurological complications of liver transplantation in adult versus pediatric patients. Transplantation 1994;58:447-450.

15. Vazquez de Prada JA, Martin-Duran R, Garcia-Monco C, et al. Cyclosporine neurotoxicity in heart transplantation. J Heart Transplant 1990;9:581-583.

16. Zétola VHF, Scola RH, Pasquini R, Werneck LC. Investigação de neuropatia periférica durante o período recente do transplante de medula óssea. Arq Neuropsiquiatr 1998;56:267-273

17. Atkinson K, Biggs J, Darveniza P, Boland J, Concannon A, Dodds A. Spinal cord and cerebellar-like syndromes associated with the use of cyclosporine in human recipients of allogeneic marrow transplants. Transplant Proc 1985;17:1673-1675.

18. Bechstein WO. Neurotoxicity of calcineurin inhibitors: impact and clinical management. Transpl Int 2000;13:313-326.

19. Schumacher JM, Ellias SA, Palmer EP, et al. Transplantation of embryonic porcine mesencephalic tissue in patients with PD. Neurology 2000;54:1042-1050.

20. Hauser RA, Freeman TB, Snow BJ, et al. Long-term evaluation of bilateral fetal nigral transplantation in Parkinson disease. A rch Neurol 1999;56:179-187.

21. Borlongan CV, Freeman TB, Hauser RA, Cahill DW, Sanberg PR. Cyclosporine-A increases locomotor activity in rats with 6-hydroxydopamine-induced hemiparkinsonism: relevance to neural transplantation. Surg Neurol 1996;46:384-388.

22. Fienberg AA, Hiroi N, Mermelstein PC, et al. DARPP-32: regulator of the efficacy of dopaminergic neurotransmission. Science 1998;281: 838-842.

23. Meyer MA. Elevated basal ganglia glucose metabolism in cyclosporine neurotoxicity: a positron emission tomography imaging study. J Neuroimaging 2002;12:92-93.

24. Borlongan CV, Stahl CE, Fujisaki T, Sanberg PR, Watanabe S. Cyclosporine A-induced hyperactivity in rats: is it mediated by immunosuppression, neurotrophism, or both? Cell Transplant 1999;8:153-159.

25. Tsujikawa K, Dan Y, Nogawa K, et al. Potentiation of domperidoneinduced catalepsy by a P-glycoprotein inhibitor, cyclosporin A. Biopharm Drug Dispos 2003;24:105-114. 